viện là $88,1 \%$ nên cấy phân khó tìm ra vi khuẩn gầy bệnh.

\section{KẾT LUẬN}

Trẻ tiêu chảy cấp phân máu thường có biểu hiện chán ăn, sốt, hậu môn sưng đỏ, mót rặn khi đi ngoài. Xét nghiệm máu thường gặp tăng bạch cầu và CRP. Tỷ lệ phát hiện vi khuẩn qua nuôi cấy thấp.

\section{TÀI LIÊU THAM KHẢO}

1. WHO, Diarrhoeal disease. 2017.

2. Bưi Thị Hồng Thắm, Nguyễn Anh Tuấn. Hoàng Lê Phúc. Đặc điểm của tiêu máu ở trẻ em từ $2-6$ tháng tuổi tại khoa Tiêu hóa BV Nhi đồng I. Tạp chí nghiên cứu y học. 2010;15(3): 160-164.

3. Nguyê̂n Phước Trướng. (2015). Đạ̣c điểm dịch tê̂, lâm sàng và vi sinh tiêu chảy cấp phân máu ở tré nhỏ.Luận văn bác sĩ chuyên khoa cấp II. Trường đại học Y Dược Thành phố Hồ Chí Minh.

4. Nguyển Phan Lượng. (2018). Nghiên cứu một sổ đạc điểm dịch tể học, lâm sang, cận lâm sàng tiêu chảy cấp do vi khuẩn ở trẻ em điêu trị tại bệnh viện nhi trung ương. Luận văn thạc sỹ y học. Trường đại học Y Hải Phòng.
5. Nguyễn Thị Thanh Tâm, Nguyễn Thị Việt Hà, Đảnh giá một số yếu tô nguy cơ của tiêu chảy kéo dài nhiềm khuẩn ở trẻ em $6-24$ tháng tuổi tai bênh viên Nhi trung, Tạp chí $Y$ học thực hànhi. 2017; 10ं48: 87-90

6. Lê Công Dần, Ngôo Thị Thi, Bùi Thị Mùi và cộng sự. Tỷ lế nhiềm và mức độ đáp ứng kháng sinh của các vi sinh vât gây bênh ở bênh nhân mắc tiêu chảy tại bệnh viện nhi Trung ướng. Tạp chí nghiên cứu y học. 2006;44(4): 52-55

7. Arvola T, et al (2006), "Rectal bleeding in infancy: Clinical, allergological, and micrbiological examination.", Pediatrics, (117), pp. 760-768,

8. Hoàng Ngọc Anh, Đặng Thị Thúy Hà, Lương Thị Nghiếm. Đặc điểm lâm sàng, cận lâm sàng của bệnh nhi tiêu chảy cấp tại bệnh viện Nhi Trung ương. Tap Chí Nghiên cứu và Thực hành Nhi khoa. 2020; 4(3): $50-54$

9. Addisu Assefa, Mengistu Girma (2019). "Prevalence and antimicrobial susceptibility patterns of Salmonella and Shigella isolates among children aged below five years with diarrhea attending Robe General Hospital and Goba Referral Hospital, South East Ethiopia" Trop Dis Travel Med Vaccines 5, 19 https://doi.org/10.1186/s40794-019-0096-6

\title{
HIỆU QUẢ BỔ SUNG SỮA CÔNG THỨC LÊN TÌNH TRẠNG DINH DƯỡNG, SỨC KHỎE CỦA TRẺ 36-60 THÁNG TÛ̉I
}

\section{TÓM TẮT}

Nghiên cứu can thiệp có đối chứng nhằm đánh giá hiệu quả bổ sung sữa công thức lên tình trạng dinh dữ̛̃ng, sức khỏe đối với trẻ 36-60 tháng tuổi. Nghiên cứu được hoàn thành tại Thái Bình vào tháng 5/2019 với 89 trẻ nhóm can thiệp bổ sung sữa công thức 2 lần/ngày trong 3 tháng và̀ 90 trẻ nhóm chứng với chế độ ăn thông thường. Kêt quả nghiên cứu cho thấy bổ sung sữa công thức đã có tác động tích cực ở nhóm can thiệp so với nhóm chứng: tăng cân, tăng chiêu cao sau 2 tháng can thiệp với mức có ý nghĩa thống kê $(p<0,05)$. Sau 4 tháng can thiêpp, mức tăng cân nặng trung bình nhiêu hơn $0,4 \mathrm{~kg}(1,5 \pm 0,4 \mathrm{~kg}$ so với $1,1 \pm 0,6 \mathrm{~kg})$; mức tăng chiêu cao trung bình nhiều hơn $0,5 \mathrm{~cm}(2,6 \pm 0,8 \mathrm{~cm}$ so với $2,1 \pm 0,8 \mathrm{~cm})$ với mức có ý nghĩa thống kê $(p<0,05)$; Cải thiện tình trạng biếng ăn với mức có ý nghĩa thống kê $(p<0,05)$. Có xu hướng cải thiện tình trạng nhiểm khuẩn hố hấp, khó ngủ nhưng số không có ý nghĩa thống kê $(p>0,05)$.

Tư khóa: đa vi chất, sữa công thức, trẻ mẫu giáo, chiều cao, cân nặng

\footnotetext{
1 Trường Đại hoc Y Hà Nôi

2Viện Y học Ứng dụng Việt Nam

Chịu trách nhiệm chính: Phạm Quốc Hùng

Email: phamquochung@hmu.edu.vn

Ngày nhận bài: 14.5.2021

Ngày phản biện khoa học: 5.7.2021

Ngày duyệt bài: 16.7.2021
}

Phạm Quốc Hùng', Phạm Văn Hoan²

\section{SUMMARY}

\section{EFFECTS OF FORMULA SUPPLEMENT ON NUTRITION STATUS AND HEALTH OF PRESCHOOL CHILDREN AGED 36-60 MONTHS}

A controlled intervention study evaluated the effect of formula supplementation on nutritional status and health of children aged 36-60 months. The study was completed in Thai Binh in May 2019 with 89 children in the intervention group supplementing with formula milk twice a day for 3 months, and 90 children in the control group with a regular diet. The study results showed that supplementing with formula had a positive effect in the intervention group compared with the control group: weight gain, height increase after 2 months of intervention with statistical significance $(p<0.05)$. The average weight gain was $0.4 \mathrm{~kg}$ more $(1.5 \pm 0.4 \mathrm{~kg}$ versus $1.1 \pm 0.6 \mathrm{~kg})$; the average height increase was $0.5 \mathrm{~cm}$ more $(2.6 \pm 0.8 \mathrm{~cm}$ versus $2.1 \pm 0.8 \mathrm{~cm})$ with statistical significance $(p<0.05)$; There was improved anorexia with statistical significance $(p<0.05)$. There was a tendency to improve respiratory infections and sleep problems, but the differencies were not statistically significant $(p>0.05)$.

Keywords: micronutrients, formula milk, preschool student, height, weight

I. ĐẶT VẤN ĐỀ

Tình trạng suy dinh dưỡng (SDD) của trẻ em, 
đặc biệt là vùng nông thôn Việt Nam còn là vấn đề sức khỏe quốc gia ảnh hưởng đến tầm vóc, chiều cao, trí tuệ và sức lao động của người Việt Nam và được ngành y tế và Chính phủ đặc biệt quan tâm[1]. Một trong những biện pháp hữu hiệu là sử dụng sữa được bổ sung vi chất dinh dưỡng (VCDD) thông qua sữa bổ sung cho trẻ nhỏ [2],[3]. Tuy nhiên, thành phần, hàm lượng sữa bồ sung sao cho cân đối, phù hợp còn là vấn đề cần nghiên cứu. Hiện nay trên thị trường có một số loại sữa công thức có thể phù hợp cho các can thiệp dinh dưỡng. Nghiên cứu này sẽ tiến hành đánh giá hiệu quả của một loại sản phẩm dinh dưỡng có thành phần, năng lượng phù hợp với hướng dẫn của Bộ Y tế và WHO [4] đối với tình trạng dinh dưỡng, sức khỏe ở trẻ mẫu giáo (36-60 tháng tuổi).

\section{II. ĐỐI TƯợNG VÀ PHƯƠNG PHÁP NGHIÊN CỨU}

Đối tượng nghiên cứu: trẻ 36-60 tháng tuổi ở hai trường mẫu giáo thuộc huyện Tiền Hải, tỉnh Thái Bình đáp ứng tiêu chuẩn chấp nhận và loại trừ nghiên cứu. Tiêu chuẩn lựa chọn: Trẻ theo học tại trường; không mắc các dị tật bẩm sinh, khuyết tật về tâm thần, vận động hoặc trẻ mắc các bệnh mạn tính; được bố mẹ/người giám hộ đồng ý. Tiêu chuẩn loại trừ: đang có bệnh; thừa cân, béo phì; đang sử dụng các sản phẩm bổ sung dinh dưỡng, tham gia nghiên cứu khác.

Thiết kế nghiên cứu: Nghiên cứu thử nghiệm can thiệp cộng đồng có đối chứng.

Thời gian: từ tháng 6/2018 đến 3/2019.

Cỡ mầu, chọn mẩu: Có 179 trẻ mẫu giáo

\section{KẾT QUẢ NGHIÊN CỨU}

Tổng số có 179 trẻ mẫu giáo tham gia nghiên cứu gồm 90 trẻ nhóm chứng và 89 trẻ nhóm can thiệp.

\section{Bảng 1. Đặc điểm hai nhóm trước khi can thiệp}

\begin{tabular}{|c|c|c|c|c|}
\hline Chỉ số & $\begin{array}{c}\text { Nhóm chứng } \\
(\mathrm{n}=90)\end{array}$ & $\begin{array}{c}\text { Nhóm can thiệp } \\
(\mathrm{n}=90)\end{array}$ & $\begin{array}{c}\text { Chung } \\
(\mathrm{n}=179)\end{array}$ & $\mathbf{p}$ \\
\hline Tỷ lệ trẻ nam & $43,3 \%$ & $44,9 \%$ & $44,1 \%$ & $>0,05^{\mathrm{a}}$ \\
\hline Tuối $($ tháng) & $49,3(33,9 ; 55,2)$ & $50,3(34,6 ; 54,9)$ & $49,9(34,0 ; 55,0)$ & $>0,05^{\mathrm{b}}$ \\
\hline Cân nặng $(\mathrm{kg})$ & $13,4(11,3 ; 16,5)$ & $13,9(11,2 ; 18)$ & $13,6(11,2 ; 17,2)$ & $>0,05^{\mathrm{b}}$ \\
\hline Chiều cao $(\mathrm{cm})$ & $97(88,4 ; 108,8)$ & $99,7(89,2 ; 111)$ & $98,5(89,1 ; 110,4)$ & $>0,05^{\mathrm{b}}$ \\
\hline SDD nhẹ cân & $12,22 \%$ & $11,24 \%$ & $11,73 \%$ & $>0,05^{\mathrm{a}}$ \\
\hline
\end{tabular}

a) $\mathrm{Chi}^{2}$ test; b)Mann-Whitney test;

Bảng 1 cho thây trước can thiệp, không có sự khác biệt có ý nghĩa thống kê (YNTK) $(p>0,05)$ giữa nhóm can thiệp và nhóm chứng về các chỉ số giới, tuổi, chiều cao, cân nặng, và tỷ lệ SDD.

Bảng 2. Hiệu quả can thiệp đôî với chiều cao của tré

\begin{tabular}{|c|c|c|c|c|}
\hline Thời điểm & $\begin{array}{c}\text { Nhóm chứng } \\
(\mathrm{n}=90)\end{array}$ & $\begin{array}{c}\text { Nhóm can thiệp } \\
(\mathrm{n}=89)\end{array}$ & Chung $(\mathrm{n}=179)$ & p-value $^{\mathbf{c}}$ \\
\hline T0 & $98,0 \pm 6,4$ & $99,7 \pm 7,0$ & $98,9 \pm 6,7$ & $>0,05$ \\
\hline T1 & $98,5 \pm 6,7$ & $100,3 \pm 6,9$ & $99,4 \pm 6,8$ & $>0,05$ \\
\hline T1-T0 & $0,5 \pm 0,2$ & $0,6 \pm 0,2$ & $0,5 \pm 0,2$ & $>0,05$ \\
\hline T2 & $98,9 \pm 6,7$ & $100,9 \pm 7,0$ & $99,9 \pm 6,9$ & $>0,05$ \\
\hline
\end{tabular}




\begin{tabular}{|c|c|c|c|c|}
\hline T2-T0 & $1,0 \pm 0,5$ & $1,2 \pm 0,4$ & $1,1 \pm 0,4$ & $<0,05$ \\
\hline T3 & $99,5 \pm 6,5$ & $101,6 \pm 7,1$ & $100,5 \pm 6,9$ & $>0,05$ \\
\hline T3-T0 & $1,6 \pm 0,7$ & $1,9 \pm 0,5$ & $1,7 \pm 0,6$ & $<0,05$ \\
\hline T4 & $100,2 \pm 7,0$ & $102,4 \pm 7,0$ & $101,3 \pm 7,0$ & $<0,05$ \\
\hline T4-T0 & $2,1 \pm 0,8$ & $2,6 \pm 0,8$ & $2,4 \pm 0,8$ & $<0,05$ \\
\hline
\end{tabular}

Số liệu được trình bày dưới dạng $\bar{X} \pm S D$; $\left.{ }^{c}\right)$ T-test

Bảng 2 cho thấy, mức tăng chiều cao hàng tháng ở nhóm can thiệp cao nhóm chứng ngay sau 1 tháng can thiệp (T1). Mức tăng chiêu cao hàng tháng đạt cao nhất tại tháng thứ 4 (nhóm chứng tăng $0,6 \mathrm{~cm}$, nhóm can thiệp tăng $0,8 \mathrm{~cm}$ ). Tại thời điểm T4, chiều cao trung bình của nhóm can thiệp là $102,4 \mathrm{~cm}$, cao hơn có YNTK so với nhóm chứng $(100,2 \mathrm{~cm})$. Mức tăng chênh lệch nhóm can thiệp và nhóm chứng là $0,5 \mathrm{~cm}(2,6 \mathrm{~cm}$ so với $2,1 \mathrm{~cm})$ có YNTK $(p<0,05)$.

Bảng 3. Hiệu quả can thiệp đôi với cân nặng của tré

\begin{tabular}{|c|c|c|c|c|}
\hline Thời điểm & $\begin{array}{c}\text { Nhóm chứng } \\
(n=90)\end{array}$ & $\begin{array}{l}\text { Nhóm can thiệp } \\
(n=89)\end{array}$ & Chung $(n=179)$ & p-value ${ }^{c}$ \\
\hline T0 & $13,7 \pm 1,5$ & $14,1 \pm 2,1$ & $13,9 \pm 1,9$ & $>0,05$ \\
\hline T1 & $14,1 \pm 1,6$ & $14,6 \pm 2,1$ & $14,4 \pm 1,9$ & $>0,05$ \\
\hline T1-T0 & $0,5 \pm 1,1$ & $0,5 \pm 0,1$ & $0,5 \pm 0,1$ & $>0,05$ \\
\hline $\mathrm{T} 2$ & $14,1 \pm 1,6$ & $14,8 \pm 2,2$ & $14,4 \pm 2,0$ & $<0,05$ \\
\hline T2-T0 & $0,4 \pm 0,5$ & $0,7 \pm 0,4$ & $0,5 \pm 0,5$ & $<0,05$ \\
\hline T3 & $14,4 \pm 1,6$ & $15,1 \pm 2,2$ & $14,8 \pm 1,9$ & $<0,05$ \\
\hline T3-T0 & $0,7 \pm 0,4$ & $1,0 \pm 0,4$ & $0,9 \pm 0,4$ & $<0,05$ \\
\hline T4 & $14,8 \pm 1,6$ & $15,6 \pm 2,2$ & $15,1 \pm 2,0$ & $<0,05$ \\
\hline T4-T0 & $1,1 \pm 0,6$ & $1,5 \pm 0,4$ & $1,3 \pm 0,6$ & $<0,05$ \\
\hline
\end{tabular}

Số liệu được trình bày dưới dạng $\left.\bar{X} \pm S D ;{ }^{c}\right)$ T-test

Bảng 3 cho thây cân nặng của nhóm can thiệp cao hơn có YNTK $(p<0,05)$ kể từ thời điểm T2 sau hai tháng can thiệp. Tại thời điểm kết thúc can thiệp, cân nặng của nhóm can thiệp cũng cao hơn có YNTK $(p<0,05)$ so với nhóm chứng $(15,6 \mathrm{~kg}$ so với $14,8 \mathrm{~kg})$. Chênh lệch mức tăng giữa hai nhóm là $0,4 \mathrm{~kg}(1,5 \mathrm{~kg}$ so với $1,1 \mathrm{~kg})$ có YNTK $(\mathrm{p}<0,05)$.

\section{Bảng 4. Hiệu quả can thiệp đôi với môt số chi số sức khỏe}

\begin{tabular}{|c|c|c|c|c|c|}
\hline \multirow[b]{2}{*}{ Chỉ số } & \multicolumn{2}{|c|}{ Trước can thiệp } & \multicolumn{2}{|c|}{ Sau can thiệp } & \multirow{2}{*}{$\begin{array}{c}\text { p- } \\
\text { value }\end{array}$} \\
\hline & Nhóm chứng & Nhóm can thiệp & Nhóm chứng & Nhóm can thiệp & \\
\hline nhiêm khuấn hô hấp & $66,67 \%$ & $46,67 \%$ & $44,94 \%$ & $39,33 \%$ & $>0,05$ \\
\hline biếng ăn & $94,4 \%$ & $88,8 \%$ & $94,1 \%$ & $75,3 \%$ & $<0,05$ \\
\hline khó ngủ & $40 \%$ & $24,7 \%$ & $17,8 \%$ & $14,6 \%$ & $>0,05$ \\
\hline
\end{tabular}

a) $\mathrm{Chi}^{2}$ test

Trước can thiệp (TO) nhóm can thiệp và nhóm chứng có tỷ lệ \% nhiễm khuẩn hồ hấp, biếng ăn, khó ngủ chênh lệch nhau ít không có YNTK. Sau can thiệp, nhóm can thiệp đã có cải thiện hơn nhóm chứng về tỷ lệ biếng ăn $(75,3 \%$ so với $94,1 \%)$ với mức có YNTK $(p<0,05)$; có $x u$ hướng cải thiện nhiễm khuẩn hô hấp (39,33\% so với $44,94 \%)$; khó ngủ (14,6\% so với $17,8 \%$ ); nhưng những sự khác biệt này không có YNTK $(p>0,05)$.

Hình 1 thể hiện kết quả tỷ lệ không uống sữa do các lý do khác nhau như nghỉ học, nghî ốm là $2 \%$; tỷ lệ uống không hết $1 / 2$ lượng sữa là $7 \%$, tỷ lệ uống đủ sữa là $91 \%$. Ngoài ra kết quả nghiên cứu cũng ghi nhận hiện tượng nôn, ói, phản ứng với sữa rất ít khi xảy ra và không thấy sự khác biệt giữa nhóm can thiệp và nhóm chứng. Chương trình bổ sung sữa được gia đình, nhà trường, chính quyền, y tế ủng hộ.

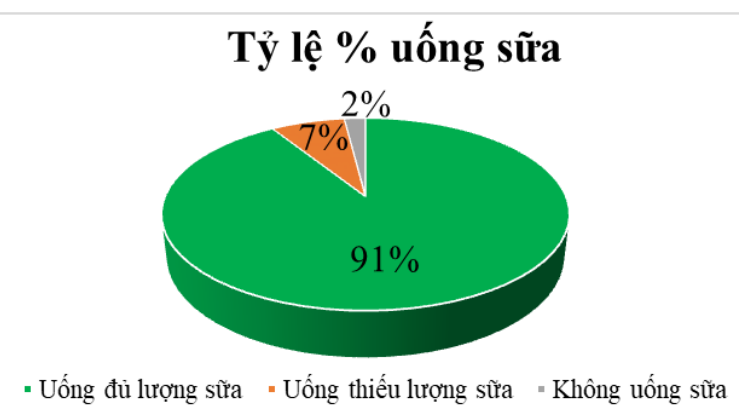

Hình 1. Tỷ lệ chấp nhận sử dụng sản phẩm

\section{BÀN LUẬN}

Kết quả nghiên cứu cho thấy bổ sung sản phẩm dinh dưỡng cao năng lượng đã có tác động tích cực ở nhóm can thiệp so với nhóm chứng: tăng cân, tăng chiều cao sau 2 tháng can thiệp với mức có ý nghĩa thống kê $(p<0,05)$. Sau 4 tháng can thiệp, mức tăng cân nặng trung bình 
nhiều hơn $0,4 \mathrm{~kg}(1,5 \pm 0,4 \mathrm{~kg}$ so với $1,1 \pm 0,6 \mathrm{~kg})$; mức tăng chiều cao trung bình nhiều hơn $0,5 \mathrm{~cm}$ $(2,6 \pm 0,8 \mathrm{~cm}$ so với $2,1 \pm 0,8 \mathrm{~cm})$ với mức có YNTK $(p<0,05)$; Điều này có thể lý giải rằng nhóm đối tượng can thiệp đang thiếu dinh dưỡng trong chế độ ăn uống, sữa bổ sung đã đáp ứng kịp thời nắng lượng (432 kcal/ngày) và các chất dinh dưỡng như protein, lipid, carbohydrate hợp lý (khoảng 20-40\% nhu câu của trẻ ở lứa tuổi này), được bổ sung thêm 24 vitamin và chất khoáng quan trọng. Các vi chất này cũng ở hàm lượng đáp ứng được trên $50 \%$ nhu câu của trẻ và cân đối với nhau, do đó chúng không ảnh hưởng tới khả năng hấp thu cũng như hoạt động sinh học trong cơ thể của nhau. Trong thành phần các chất dinh dưỡng như DHA, các axit amin, lipid, loai vitamin, khoáng chất được bổ sung với một hàm lượng phù hợp, hỗ trợ hấp thu, chuyển hóa góp phần vào cải thiện tình trạng dinh dưỡng, chiêu cao, cân nặng của trẻ [3].

Cải thiên tình trang biếng ăn với mức có YNTK $(p<0,05)$. Có xu hướng cải thiện tình trạng nhiễm khuẩn hô hấp, khó ngủ nhưng số khồng có YNTK $(p>0,05)$. Lý giải cho sự cải thiện này là protein, lipid, các vitmin, khoáng chất bổ sung đã góp phần tạo ra các mạch máu mới, tổng hợp collagen, sản sinh carnitine, giúp hấp thụ tối đa chất dinh dưỡng, sản xuất các enzyme, kháng thể và hormone, giúp cơ thể tăng cường sức đề kháng và các quá trình chuyển hóa, giúp cơ thể phát triển, tăng miễn dịch giúp trẻ ăn ngủ ngon hơn [6]. Vitamin $A, D, B, C$, sắt, kẽm, đồng, iot, selen... tham gia tăng cường phát triển tế bào tác động đến chiều cao, cân nặng, hệ thống tiêu hóa, miển dịch. Các VCDD có tính chống oxy hoá có vai trò quan trọng trong việc xây dựng, tăng cường, sửa chữa hệ thống miễn dịch, tăng sức đề kháng, tăng cường tiêu hóa làm giảm biếng ăn như kẽm, selen, sắt, đồng, vitamin $A, D, C$, E.[7]. DHA, Vitamin $D$ và nhiêu vi chất khác tham gia vào điều hòa thần kinh làm giảm kích thích khó ngủ. chất xơ hòa tan (FOS/Inulin) chống táo bón rất tốt. Vitamin $\mathrm{C}, \mathrm{B} 1, \mathrm{~B} 2 \ldots$ giúp trẻ ăn ngon miệng tăng hấp thu, chuyển hóa, tác động đến tăng khối lượng cơ bắp, xương. Các vi chất khác tham gia vào các quá trình sinh tổng hợp hóc môn và các men, tham gia xây dựng tế bào như $B 12$, folic tham gia sản xuất hồng cầu, tế bào thần kinh [6]. Việc bổ sung 24 VCDD trong công thức này bổ trợ lẫn nhau có thể cho tác dụng vượt trội so với tắng cường đơn lẻ một hoặc một vài vi chất đã tác động vào hệ thống tiêu hóa, miễn dịch, chuyển hóa, thần kinh thúc đẩy tăng trưởng và tăng cường sức khỏe.
Khả năng chấp nhận sử dụng cao: $91 \%$ số trẻ uống đủ khẩu phần sữa (2 bữa/ngày trong 3 tháng). Chương trình bổ sung sữa được gia đình, nhà trường, chính quyền, $y$ tế ủng hộ. Những kết quả này có thể phù hợp với giả thiết rằng công thức sữa phù hợp với sử dụng và khả năng hấp thu, gồm năng lượng, chất béo, protein, và 24 vitamin và khoáng chất và bổ sung thêm $\mathrm{DHA}$, chất xơ hòa tan (FOS/Inulin), được tính theo nhu cầu khuyến nghị hàng ngày của Bộ $Y$ tế và $W H O$ và tính toán từ các chuyên gia nhằm hướng tới đối tượng đích cũng là một yếu tố để các phụ huynh, cô giáo, cán bộ y tể ủng hộ sử dụng sản phẩm.

\section{KẾT LUÂ̂N}

Can thiệp bổ sung sản phẩm dinh dưỡng cao năng lượng Care 100 Gold ở trẻ 36-60 tháng tuổi đã có tác động tích cực, các chỉ số dinh dưỡng, sức khỏe ở nhóm can thiệp tốt hơn so với nhóm chứng: tăng cân, tăng chiều cao sau 2 tháng can thiệp với mức có ý nghĩa thống kê $(p<0,05)$. Sau 4 tháng can thiệp, mức tăng cân nặng trung bình nhiều hơn $0,4 \mathrm{~kg}(1,5 \pm 0,4 \mathrm{~kg}$ so với $1,1 \pm 0,6 \mathrm{~kg})$; mức tăng chiêu cao trung bình nhiều hơn $0,5 \mathrm{~cm}$ $(2,6 \pm 0,8 \mathrm{~cm}$ so với $2,1 \pm 0,8 \mathrm{~cm})$ với mức có ý nghĩa thống kê $(p<0,05)$; Cải thiện tình trạng biếng ăn với mức có ý nghĩa thống kê $(p<0,05)$. Có xu hướng cải thiện tình trạng nhiễm khuẩn hô hấp, khó ngủ nhưng số không có ý nghĩa thống kê $(p>0,05)$. $91 \%$ số trẻ đảm bảo uống đủ khẩu phần sữa 2 lần/ngày.

\section{TÀI LIÊU THAM KHẢO}

1. Chính phủ (2015). Chiến lược quốc gia về dinh dưỡng giai đoạn 2011 - 2020 và tầm nhin đến năm 2030.

2. Chính phủ (2016). Chương trình sữa học đường cải thiện tình trạng dinh dưỡng góp phần nâng cao tầm vóc trẻ em mẫu giáo và tiểu học đến năm 2020.

3. Best C., Neufingerl N., Del Rosso J.M., et al. (2011). Can multi-micronutrient food fortification improve the micronutrient status, growth, health, and cognition of schoolchildren? a systematic review. Nutr Rev, 69(4), 186-204.

4. World Health Organization (2013). Essential Nutrition Actions: improving maternal, newborn, infant and young child health and nutrition. .

5. World Health Organization (2006). The WHO child growth standards. Bull World Heal Organ, 52(1), 13-17.

6. Flodin N.W. (1997). The metabolic roles, pharmacology, and toxicology of lysine. J Am Coll Nutr, 16(1), 7-21.

7. Gombart A.F., Pierre A., and Maggini S. (2020). A Review of Micronutrients and the Immune System-Working in Harmony to Reduce the Risk of Infection. Nutrients, 12(1), 123-133. 